\title{
FETUIN-A - ALPHA2-HEREMANS-SCHMID GLYCOPROTEIN: FROM STRUCTURE TO A NOVEL MARKER OF CHRONIC DISEASES PART 2. FETUIN-A - A MARKER OF INSULIN RESISTANCE AND RE- LATED CHRONIC DISEASES
}

\author{
Regina S. Komsa-Penkova, \\ Katya S. Kovacheva ${ }^{1}$, \\ Georgy M. Golemanov, \\ Veselin P. Penkov², \\ Zdravka V. Radionova ${ }^{3}$, \\ Galia B. Georgieva- \\ Alexandrova, \\ Alim V. Izmajlov
}

Division of Biochemistry, Medical University - Pleven, Bulgaria

${ }^{1}$ Division of Medical Genetics, Medical University - Pleven, Bulgaria

${ }^{2}$ Repromed Medical Centrum - Pleven, Bulgaria

${ }^{3}$ Division of Pedagogy and Psychology, Medical University - Pleven, Bulgaria

Corresponding Author:

Regina S. Komsa-Penkova Division of Biochemistry, Medical University - Pleven 1, St. Kl. Ohridski Str.

Pleven, 5800

Bulgaria

e-mail:rkomsa@gmail.com

Received: January 19, 2018

Revision received: April 09, 2018 Accepted: June 26, 2018

\section{Summary}

Fetuin-A is a secretory liver glycoprotein with multiple physiological functions such as regulation of insulin resistance, tissue calcification, bone metabolism, cellular proteolytic activity, and self-proliferative signaling.

Fetuin-A is a unique molecule which binds to the insulin receptor, modulating its sensitivity, and transducing "the physiological conditions" (serum levels of the metabolites like glucose, free fatty acids, inflammatory signals) from outside into inside the cells. Plasma fetuin-A levels correlate with reduced glucose tolerance and insulin resistance. Impaired insulin sensitivity leads to the development of metabolic syndrome, an increased risk for type 2 diabetes (T2DM), dyslipidaemias and cardiovascular diseases (CVDs). Furthermore, fetuin-A inversely correlates with inflammatory and activation biomarkers, e.g. in patients with T2DM. Thus, circulatory fetuin-A levels may have plausible predictive importance as a biomarker of risk of diabetes and negative acute phase protein. Dysregulated, it plays a crucial role in the pathogenesis of some metabolic disorders and clinical inflammatory conditions like metabolic syndrome, T2DM, CVDs, polycystic ovary syndrome (PCOS), etc.

Key words: fetuin-A, insulin resistance, T2DM, metabolic syndrome, obesity, PCOS

\section{Introduction}

Fetuin-A is a human secretory protein of liver, possessing multiple physiological and pathological functions as regulation of insulin resistance, inhibition of soft and vascular tissue calcification, bone metabolism regulation, regulation of proteolytic activity, keratinocyte migration, and tumorigenesis cell proliferative signaling [1]. It is a highly expressed glycoprotein in various fetal tissues whereas it is mainly expressed in the liver in adults [2].

\section{Structure and function}

Fetuin-A is a major plasma protein discovered independently by J. Heremans (1960) [2] and Schmid et al. (1961) [3] and named accordingly as $\alpha 2$-HeremansSchmid glycoprotein (AHSG) [4]. 
The structure of fetuin-A includes two disulfide-bonded peptides [5], forming three domains - two cystatin domains D1 and D2, and C-terminal specific region [6]. Posttranslationally, after proteolytic processing it undergoes: glycosylation [7], phosphorylation $[8,9]$ and sulfation [10]. As a glycoprotein, it contains three N-linked branched glycans [11] and four sites of O-linked glycosylation, forming approximately $23.6 \%$ of carbohydrate [12]. Posttranslational modifications may attenuate its biological stability and activity [13].

Phosphorylation of serine residues ( $\operatorname{Ser}^{120}$ and $\mathrm{Ser}^{312}$ ) is essential for fetuin-A interaction with the insulin receptor and inhibitory activity [14]. $\mathrm{Ser}^{312}$ seems to be a site of regulatory covalent modifications, whereas $\operatorname{Ser}^{120}$ was shown to be constitutively phosphorylated. Approximately $20 \%$ of fetuin-A in circulation is phosphorylated [10]. In the studies of Brown et al. (1992) and Diegielewska et al. (1996), the complementary deoxyribonucleic acid (cDNAs) encoding human, sheep, cow, rat, mouse, and pig fetuin-A were compared, and high sequence identity was shown $[15,16]$.

\section{Fetuin-A and insulin resistance}

Fetuin-A is a physiological insulin receptor inhibitor. It induces insulin resistance and alters metabolism in insulin-sensitive tissues by inhibition of the autophosphorylation of tyrosine kinase. The most affected tissues are the liver, adipose tissue, muscles, hypothalamus where it disturbs cell signaling pathways and homeostasis [17].

The role of fetuin-A in the mechanism of insulin resistance was demonstrated in animal models and humans. Acute injection of human recombinant fetuin-A in rats has shown to suppress the activity of the tyrosine kinase and insulin receptor substrate protein (IRS-1) in muscles and the liver. The mechanism of action of fetuin-A includes inhibition of the autophosphorylation of the enzyme (tyrosine kinase) and extracellular signal-regulated kinase (ERK) $1 / 2$ mitogenic signaling arm [14, 15]. Studies in fetuin-A knockout mice demonstrated increased phosphorylation of insulin receptor and improved insulin sensitivity [18]. Fetuin-A knockout mice on a high-fat diet have been found to have lower serum lipids (free fatty acid and triacylglycerol) and protected from overweight and obesity [19].

Studies in humans demonstrated that fetuin-A level was positively associated with fasting. Low levels of fetuin-A on fasting stimulated insulin release, and negatively correlated with insulin sensitivity as measured by the euglycemic hyperinsulinemic clamp [20]. High fetuin-A plasma levels predict reduced insulin sensitivity. Dysregulated insulin sensitivity leads to the development of metabolic syndrome [21], an increased risk for T2DM [22], dyslipidaemias and cardio-vascular diseases. The detailed mechanism of blocking the metabolic arm of insulin action by fetuin-A/AHSG was investigated by Goustin et al. (2013) [23].

In the study on mouse myoblasts, it was demonstrated that fetuin-A binding to the insulin receptor blocks glucose transporter type 4 (GLUT4) translocation in response to insulin action through the inhibition of autophosphorylation of the $95 \mathrm{kD} \beta$-subunit of insulin holoreceptor in a cell-free system [24]. Fetuin-A antagonizes the metabolic functions initiated by insulin receptor activation without the interference of insulin binding to the receptor. The experimental data support the suggestion of a direct interaction of fetuin-A with the insulin receptor $\beta$-subunit ectodomain, in a way that does not interfere the high-affinity insulin binding of $\alpha$-subunit of the receptor.

The developed three-dimensional model of rat AHSG indicated the putative epitope, possibly interacting with the beta-subunit ectodomain of the insulin receptor (INSR) [24]. These experiments demonstrated that fetuin-A might be an allosteric modulator of the INSR.

\section{Fetuin-A role in increased risk of T2DM}

T2DM is a major global public health threat. In 2012 there were 1.5 million deaths worldwide directly caused by diabetes (the eighth leading cause of death) as reported by WHO (2016) [25]. T2DM is mostly preventable, and evaluation of proper risk factors is essential for its prevention. The EPIC-Potsdam Study and prospective cohort study A found a positive association of fetuin-A levels with risk of T2DM [26]. Thus it was linked to the development of insulin resistance as an independent factor measured by the index of homeostasis model (HOMA-IR). 
Fetuin-A interaction with INSR and IRS-1 is suggested as a novel mechanism involved in the pathophysiology of T2DM [27].

The levels of circulating fetuin-A were demonstrated to correlate with diminished glucose tolerance, insulin resistance and T2DM in humans. The study of Norbert et al. (2008) showed that plasma fetuin-A levels are predictive for the incidence of T2DM independently of other established risk factors, particularly in individuals with elevated plasma glucose [28]. Furthermore, some studies provided data that fetuin-A is strongly associated with fat accumulation in the liver, non-alcohol induced fatty liver disease, and metabolic syndrome [29]. The investigated fetuin-A gene polymorphisms were proved to associate with T2DM, and impaired insulin sensitivity in adipocytes [30].

Fetuin-A levels reveal a divergent correlation with pro-inflammatory markers in patients with T2DM. The investigation of inflammatory mediators or activation markers in T2DM patients by Sindhu et al. (2016) demonstrated a reciprocal correlation between plasma levels of fetuin-A and interleukin (IL)-1 $\beta$, IL-7, IL-15, tumor necrosis factor alpha (TNF- $\alpha$ ), chemokine ligand (CCL)2, CCL4, soluble CD40L (sCD40L), growth related oncogene (GRO), elongation factor $F$ (EFF) 2, and vascular endothelial growth factor (VEGF) [31]. The study provided evidence that fetuin-A levels are reciprocally associated with the pro-inflammatory cytokines and biomarkers that possess a predictive value of fetuin-A as a negative acute phase protein in patients with T2DM.

Early stage pro-inflammatory cytokines interferon gamma (IFN- $\gamma$ ), IL-1 $\beta$ and TNF- $\alpha$ were demonstrated to be rather inhibitory regulators of liver synthesis of fetuin-A [32]. The negative correlation between pro-inflammatory cytokines and fetuin-A levels in T2DM patients may predict lower fetuin-A levels in the presence of increased pro-inflammatory markers.

Altogether, these investigations testify that plasma fetuin-A levels correlate with impaired glucose tolerance and insulin resistance, and inversely correlate with inflammatory and activation biomarkers in patients with T2DM. Circulatory fetuin-A levels may have plausible predictive importance as a biomarker of risk for diabetes and negative acute phase protein [33]. A systematic review of 11497 individuals,
2176 cases of T2DM and meta-analysis indicated that higher circulating fetuin-A levels were related to increased risk of T2DM. The association was gender-related and particularly evident in women. A significant relationship between fetuin-A levels with T2DM risk was demonstrated in many systematic reviews [34].

\section{The role of fetuin-A in metabolic syndrome and its components}

A close relationship of fetuin-A with metabolic syndrome has been demonstrated in crosssectional studies [35]. The suggestion that fetuin-A level in humans is related to the development of the metabolic syndrome phenotype is supported by a few studies, indicating a correlation of fetuin-A with many components of metabolic syndrome such as high blood pressure, waist circumference, and cholesterol levels [36]. In patients with coronary artery disease (non-diabetic) a higher level of fetuin-A correlated with metabolic syndrome and atherogenic lipid profile according to a study on middle-aged and elderly Chinese subjects, and the Heart and Soul Study [21, 37, 38].

Adiponectin is also known to be involved in the regulation of insulin sensitivity. It is the insulin-sensitizing adipocytokine - a valuable element of the body sensitivity and risk of CVDs. Adiponectin production may be suppressed by fetuin-A [39].

High levels of fetuin-A in the circulation appear to promote insulin resistance and, particularly in patients with diabetic nephropathy; such levels could be directly related to vascular calcification.

The cross-sectional studies provide the evidence of an essential role of low level of fetuin-A as a risk factor in dialysis patients. An association with cardiovascular and all-cause mortality was confirmed [40].

The role of fetuin-A in regulating insulin sensitivity, postprandial glucose clearance, and fat accumulation provides a new understanding of these processes. It is assumed that in the future it could be used for the novel approach to the therapy of T2DM, metabolic syndrome and insulin resistance [41].

In line with the latest data from the studies, it could be assumed that synthesis of fetuin-A can be diversely controlled in various disease 
conditions. This hepatokine could eventually serve as both positive and negative acute phase protein in various morbid states [32].

\section{Fetuin in obesity}

Recently, it was demonstrated that subcutaneous and visceral adipose tissue secrete fetuin-A.

The relationship between the circulating levels of fetuin-A and fat mass was investigated in animal studies in various conditions such as diet-induced obesity, weight loss induced by exercise, and anorexia [42]. The expression and secretion pattern of fetuin-A by adipose tissue from visceral and subcutaneous stores at various physiological and nutritional conditions indicate the relation between fat mass, body weight, and secreted fetuin-A. Adipose tissue, apart from adipocytes, contains macrophages, endothelial cells, and fibroblasts (stromal fraction) contributing to the protein/peptide secretion pattern. Furthermore, the secretomes in white adipose tissue have been identified and analyzed recently $[43,44]$.

The secretion of fetuin-A by visceral adipose tissue from anorectic animals is reduced. However, it is over-secreted by visceral adipose tissue in obesity [45]. The secretion of active phosphorylated at $\mathrm{Ser}^{321}$ residue fetuin-A by visceral adipose tissue is independent of body mass index (BMI), while the fraction of activefetuin-A secreted by subcutaneous adipose tissue augments significantly in situations of obesity [44]. Altogether, visceral adipose tissue secretes more fetuin-A than subcutaneous adipose tissue. It worth noting that secretion of fetuin-A is related to physiological and nutritional changes. Weight loss has also been proved to reduce circulating fetuin-A levels in humans [46].

Additionally, there is data proving that fetuin-A could influence adipose tissue and stimulate inflammatory cytokine production by macrophages and adipocytes and thus induce total insulin resistance.

More recently, the studies on the effects of fetuin-A on toll-like receptor 4 (TLR-4) have proved that fetuin-A acts as an endogenous lipid induced ligand of TLR-4 of adipocyte inflammation and insulin resistance [46].

Thus it might be suggested that inflammation in adipose tissue induced by free fatty acids could be mediated by fetuin- $A$ and is not a direct effect [46]. The data on the increased secretion of fetuin-A by visceral adipose tissue, and particularly the augmented proportion of the phosphorylated (active) form of fetuin-A secreted by subcutaneous adipose tissue in obese animals suggest the critical role of fetuin in deleterious obesity consequences and comorbidities aggravated by the capacity of adipose-derived fetuin-A to inhibit the insulin pathway.

\section{Fetuin role in CVD}

CVDs are one of the major causes of death in the world amounting to almost $30 \%$ of all deaths. The number of studies that indicate an association between fetuin-A and CVDs is increasing. However, a divergent relationship was reported.

Some studies demonstrated that the patients with high fetuin-A concentrations had a higher (to 4-fold increased) risk of myocardial infarction and ischaemic stroke, as compared to subjects with low fetuin-A levels [47]. The risk was gender-related, and was higher in women than in men. In a study carried out by Rancho-Bernardo, raised fetuin-A levels correlated with lower risk of CVD death in patients without T2DM [48], though in the T2DM patients there was a direct association of fetuin-A levels with CVDs [38]. A positive correlation of fetuin-A with arterial stiffness and increased intima-media thickness was detected in patients with normal renal function and in healthy subjects [49].

Furthermore, fetuin-A plays a role in the development of subclinical inflammation, by promoting cytokine expression in human monocyte and thereby might have an effect on CVD risk [37, 50].

Nonetheless, some clinical studies have reported opposite trends. Low fetuin-A levels were associated with the presence of peripheral arterial disease, atherosclerotic plaque calcification, and increased arterial stiffness. In patients with stable angina and acute myocardial infarction, fetuin-A concentrations were lower $[51,52]$. Several systematic reviews and metaanalyses evaluated the relationship between fetuin-A levels and the risk of CVDs. They provided contradictory results: the association with CVD risk in various prospective studies was found as a negative correlation (decreased serum fetuin-A level correlated with the development 
of CVDs) [53], as reflecting the progression of CVDs [54], or as inconsistent [55].

In the paper of Roos et al. (2010), a hypothesis of two-phase association of fetuin-A with vascular disease depending on the stage of atherosclerosis was suggested [56]. Higher fetuin-A circulation level in healthy diabetic and non-diabetic subjects without vascular pathology, correlated with CVD risks. However, a contradictory relationship was demonstrated in patients with established vascular disease [53]. It was assumed that in early CVD stages fetuin-A aggravates disease development due to induced insulin resistance and dyslipidemia. On the other hand, in patients with an already established CVDs high fetuin-A level was found to improve the clinical presentation, possibly due to the prevention of vascular $\mathrm{Ca}^{2+}$ deposition by fetuin-A [32].

\section{Fetuin A in stroke patients}

Of the estimated 17.3 million deaths from CVD in 2008 , representing $30 \%$ of all global deaths, $13.8 \%$ were due to stroke. The primary cause of stroke includes hypertension, atherosclerosis leading to coronary artery disease, dyslipidemia, heart disease, and subclinical inflammation. The risk of stroke increases with age, and in subjects over 55, it doubles twice per decade. Patients with diabetes are at a higher risk of stroke than those without diabetes.

The inflammatory responses in cerebral ischemia are forced by specific mediators secreted by neurons and microglia, as well as by infiltration of peripheral immune cells such as macrophages.

The correlation of elevated mediators of inflammation and ischemic stroke was demonstrated in several studies. Sezer et al. (2014) investigated the levels of fetuin-A, Pentraxin-3, and serum amyloid $\mathrm{A}$ in a group of patients with ischemic stroke. Their results proved a significant correlation between the inflammatory factors and disease severity and progression [57]. The positive correlation between high plasma fetuin-A concentrations and a significantly higher risk of ischemic stroke and myocardial infarction was found in the patients from the EPIC-Potsdam Study with ischemic stroke and myocardial infarction [49, 58]. A study of a group of 200 patients with stroke proved significantly higher fetuin-A levels in the group of patients with carotid plaque formation. Increased plasma inflammatory biomarker levels were accompanied by a high risk of carotid plaque formation and instability [59]. However, in a study of a female group with ischemic stroke, no significant relationship of the concentration of fetuin-A and risk of embolic or thrombotic stroke was found [60].

An investigation of ischemic brain tissue in an animal model of focal cerebral ischemia demonstrated that the concentrations of fetuin-A changed in a time-dependent manner. The concentration of fetuin-A started to elevate around 2 and $6 \mathrm{~h}$, reaching the highest values between 24 to $48 \mathrm{~h}$ and restored to baseline $72 \mathrm{~h}$ after middle cerebral artery occlusion [61]. As inflammation plays an important role in acute ischemic stroke, the investigation of the relationship between acute ischemic stroke and serum fetuin-A level could produce new insight on the disease development and progression.

\section{Polycystic ovary syndrome (PCOS)}

PCOS is a heterogeneous endocrine disorder. Its prevalence depends on the criteria applied from $6 \%$ to $10 \%$ according to the U.S. National Institutes of Health (NIH) criteria and lipidinduced $15 \%$ according to Rotterdam criteria $[62,63]$. The clinical expression varies including oligo- or anovulation, hyperandrogenemia, and polycystic ovaries and commonly manifests in early reproductive years.

Women with PCOS are also more predisposed to insulin resistance and metabolic syndrome. Studies on the impact of fetuin-A in metabolic syndrome and insulin resistance inspired interest in its role in the patient with PCOS [64].

It was shown that roughly $60-80 \%$ of women with PCOS are with insulin resistance, reaching a higher percentage when obese [65]. Some investigations assess the contribution of fetuin-A to triggering the processes, which leads to the development of PCOS and its important symptoms: insulin resistance and androgen excess [63, 64].

A positive correlation of fetuin-A with insulin, a homeostatic model assessment of insulin resistance (HOMA-IR) and free androgen index (FAI) in PCOS patients was demonstrated in some studies [66]. Multiple regression analysis 
revealed that free androgen index was strongly related to the serum fetuin-A level. Serum fetuin-A level was related to insulin resistance and ovarian hyperandrogenism in women with PCOS [67].

Fetuin-A could be assumed as an important factor linking insulin resistance with obesity. Reduced insulin sensitivity and the resulting hyperinsulinemia were much more expressed than it was foreseen, as far as BMI was concerned in PCOS patients. It proves significant disturbances in metabolism in both obese and non-obese PCOS patients. In general, obesity in PCOS patients is associated with more expressed insulin resistance, hyperandrogenemia, and fertility problems.

In certain studies, higher serum concentrations of fetuin-A were found in obese women without PCOS, as compared to lean women. These concentrations decreased after major weight loss.

PCOS women with reproductive problems searching artificial insemination with intracytoplasmic sperm injection (ICSI) showed no significant difference in serum fetuin-A levels, as compared to ICSI-treated non-PCOS ones [68]. However, fetuin-A level in follicular fluid of non-PCOS women was significantly higher than that in the follicular fluid of women with PCOS. Furthermore, there was no significant difference in serum or follicular fluid of fetuin-A levels between PCOS women who succeeded in becoming pregnant and those who did not.

Since fetuin-A is a natural inhibitor of INSR activity, the association of fetuin-A with insulin resistance during pregnancy was investigated in several studies with contradictory results. In a case-control study by Farhan et al (2012), acute glucose intake on performing glucose tolerance test and its influence on serum fetuin-A level was investigated in women with gestational diabetes mellitus (GDM) $(n=10)$ in the early third trimester and healthy controls $(n=10)$ [69]. A correlation between fetuin-A and body mass index was demonstrated. However, no significant association with neither insulin sensitivity nor with insulin and C-peptide levels was found. There was no correlation with fetuin-A in later pregnancy or after pregnancy. In the study of Kalabay et al (2002), including thirty pregnant patients with GDM; one hundred four healthy pregnant women and the same number of non-pregnant controls, the maternal serum levels of fetuin-A were assessed [70]. A correlation between serum fetuin levels and maternal parameters such as fasting C-peptide and C-peptide/glucose ratio was established, indirectly indicating the risk of insulin resistance. The results regarding a relationship with serum fetuin-A levels are rather contradictory.

The mean serum fetuin-A level was found to be considerably higher as compared to healthy controls in the investigation of Abali et al. (2013) [71]. The study by Gulhan et al. (2012), on the other hand, revealed no difference between healthy controls and the patients with PCOS with regard to the level of fetuin-A [72]. Most likely, these controversial results might be attributed to the difference in insulin resistance and euglycemic control. Further studies are needed to assess the role of fetuin-A in PCOS patients and related fertility problems.

\section{Conclusions}

The role of fetuin-A in insulin resistance and related morbidities was investigated in numerous studies. The immediate impact on the physiological regulation of the activity of INSR, through attenuation of its action and the response to hyperglycaemia, dyslipidemia, $\mathrm{Ca}^{2+}$ level and inflammatory condition was discussed. The role of fetuin-A as a potential disease marker, particularly concerning insulin resistance, T2DM, metabolic syndrome, CVDs, ischemic stroke, reproductive problems in PCOS or pregnancy complications (GDM, preeclampsia) was considered, as well as eventual drug management of these conditions.

\section{Acknowledgments}

This review and the study were financially supported by Medical University of Pleven (Project 21/2016)

\section{References}

1. Mori K, Emoto M, Inaba M. Fetuin-A: a multifunctional protein. Recent Pat Endocr Metab Immune Drug Discov. 2011;5(2):124-46.

2. Hermans JF. Les Globuline, Sériques du Système Gamma. Masson et Cie, editor. Paris: Arscia- 
Bruxelles; 1960.

3. Schmid K, Burgi W. Preparation and properties of the human Ba-a2 glycoproteins. Biochim Biophys Acta. 1961;47:440-3.

4. Pedersen KO. Fetuin, a new globulin isolated from serum. Nature. 1944; 154:575.

5. Gejyo, F, Schmid K. Purification and characterization of the two forms of human plasma $\alpha_{2}$ HS-glycoprotein. Biochim Biophys Acta. 1981; 671(1):78-84.

6. Kübler D, Gosenca D, Wind $M$, Heid H, Friedberg I, Jahnen-Dechent W, et al. Proteolytic processing by matrix metalloproteinases and phosphorylation by protein kinase CK2 of fetuin-A, the major globulin of fetal calf serum. Biochimie..2007;89(3):410-8.

7. Bendiak B, Harris-Brandts M, Michnick SW, Carver JP, Cumming DA. Separation of the complex asparagine-linked oligosaccharides of the glycoprotein fetuin and elucidation of three triantennary structures having sialic acids linked only to galactose residues. Biochemistry.1989;28(15):6491-9.

8. Ohnishi T, Nakamura O, Arakaki N, Daikuhara Y. Effect of phosphorylated rat fetuin on the growth of hepatocytes in primary culture in the presence of human hepatocyte-growth factor. Evidence that phosphorylated fetuin is a natural modulator of hepatocyte-growth factor. Eur J Biochem. 1997; 243(3):753-61.

9. Haglund AC, Ek B, Ek P. Phosphorylation of human plasma alpha2-Heremans-Schmid glycoprotein (human fetuin) in vivo. Biochem J. 2001;357(2):437-45.

10. Hortin GL, Schilling M, Graham JP. Inhibitors of the sulfation of proteins, glycoproteins, and proteoglycans. Biochem Biophys Res Commun.1988;150(1):342-8.

11. Naseem F, Khan RH, Haq SK, Naeem A. Characterization of molten globule state of fetuin at low $\mathrm{pH}$. Biochim Biophys Acta. 2003;1649(2):16-70.

12. Guttman M, Weinkam P,2 Sali A, Lee KK. Allatom ensemble modeling to analyze smallangle $x$-ray scattering of glycosylated proteins. Structure. 2013; 21(2):321-31.

13. Auberger P, Falquerho L, Contreres JO, Pages G, Le Cam G, Rossi B, et al. Characterization of a natural inhibitor of the insulin receptor tyrosine kinase: cDNA cloning, purification, and antimitogenic activity. Cell.1989;58(4):631-40.

14. Mathews ST, Chellam N, Srinivas PR, Cintron VJ, Leon MA, Goustin AS. Alpha2-HSG, a specific inhibitor of insulin receptor autophosphorylation, interacts with the insulin receptor. Mol Cell Endocrinol. 2000;164(1-2):87-98.

15. Brown WM, Dziegielewska KM, Saunders' NR,
Christie DL, Nawratil P, Muller-Esterl W. The nucleotide and deduced amino acid structures of sheep and pig fetuin. Common structural features of the mammalian fetuin family. Eur J Biochem. 1992;205(1):321-31.

16. Dziegielewska K, Brown WM, Deal, A, Foster KA, Fry EJ, Saunders NR. The expression of fetuin in the development and maturation of the hemopoietic and immune systems. Histochem Cell Biol. 1996;106(3):319-30.

17. Carvalho BM, Abdalla Saad MJ. Influence of gut microbiota on subclinical inflammation and insulin resistance. Mediators Inflamm. 2013;1-13.

18. Cintrón VJ, Ko MS, Chi KD, Gross JP, Srinivas PR, Goustin AS, et al. Genetic mapping and functional studies of a natural inhibitor of the insulin receptor tyrosine kinase: the mouse ortholog of human alpha2-HS glycoprotein. Int J Exp Diabetes Res. 2001;1(4):249-63.

19. Mathews ST, Rakhade S, Zhou X, Parker GC, Coscina DV, Grunberger G. Fetuin-null mice are protected against obesity and insulin resistance associated with aging. Biochem Biophys Res Commun. 2006;350(2):437-43.

20. Dabrowska AM, Tarach JS, Wojtysiak-Duma B, Duma D. Fetuin-A (AHSG) and its usefulness in clinical practice. Review of the literature. Biomed Pap Med Fac Univ Palacky Olomouc Czech Repub. 2015;159(3):352-9.

21. Ix JH, Shlipak MG, Brandenburg VM, Ali S, Ketteler M, Whooley MA. Association between human fetuin-A and the metabolic syndrome: data from the Heart and Soul Study. Circulation. 2006;113(14):1760-7.

22. Taylor R. Insulin resistance and type 2 diabetes. Diabetes. 2012; 61(4):778-9.

23. Goustin AS, Derar N,.Abou-Samra AB. Ahsgfetuin blocks the metabolic arm of insulin action through its interaction with the $95-\mathrm{kD} \beta$-subunit of the insulin receptor. Cell Signal. 2013;25(4):9818 .

24. Goustin A-S. Human Ahsg (fetuin-A) mature protein (model in PyMol) [Internet]. 2012 Jun [cited 2018 Jun 10]. Available from: https://www. youtube.com/watch? $\mathrm{v}=\mathrm{C} 212 \mathrm{~S} \_$owySw

25. WHO. Global report on diabetes [Internet]. 2016 [cited 2018 Jun 10]. Available from:http://apps.who.int/iris/bitstream/ handle/10665/204871/9789241565257_eng.pdf;j sessionid=B0D9E4564FCBF06628ABAC20F1C C29D6? sequence $=1$

26. Jacobs S, Kröger J, FloegelA, Boeing H, Drogan D, Pischon T, et al. Evaluation of various biomarkers as potential mediators of the association between coffee consumption and incident type 2 diabetes in the EPIC-Potsdam Study..Am J Clin Nutr. 2014;100(3):891-900. 
27. Lorant DP, Grujicic M, Hoebaus C, Brix JM, Hoellerl F, Schernthaner G, et al. Fetuin-A levels are increased in patients with type 2 diabetes and peripheral arterial disease. Diabetes Care. 2011;34(1):156-61.

28. Norbert S, Fritsche A, Weikert C, Boeing H, Joost HG, Haring HU, et al. Plasma fetuin-A levels and the risk of type 2 diabetes. Diabetes. 2008;57(10):2762-7.

29. Reinehr T, Roth CL. Fetuin-A and its relation to metabolic syndrome and fatty liver disease in obese children before and after weight loss. J Clin.Endocrinol Metab. 2008;93(11):4479-85.

30. Siddiq A, Lepretre F, Hercberg S, Froguel P, Gibson F. A synonymous coding polymorphism in the alpha2-Heremans-schmid glycoprotein gene is associated with type 2 diabetes in French Caucasians. Diabetes. 2005;54(8):2477-81.

31. Sindhu S, Akhter N, Shenouda S, Wilson A,

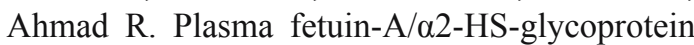
correlates negatively with inflammatory cytokines, chemokines and activation biomarkers in individuals with type-2 diabetes. BMC Immunol. 2016;17:33.

32. Li W, Zhu S, Li J, Huang Y, Zhou R, Fan X, et al. A hepatic protein, fetuin-A, occupies a protective role in lethal systemic inflammation. PLoS One. 2011;6(2):e16945.

33. Guo VY, Cao B, Cai C, Cheng KK, Cheung BMY. Fetuin-A levels and risk of type 2 diabetes mellitus: a systematic review and meta-analysis. Acta Diabetol. 2018;55(1):87-98.

34. Roshanzamir F, Miraghajani M, Rouhani MH, Mansourian M, Ghiasvand R, Safavi SM. The association between circulating fetuin-A levels and type 2 diabetes mellitus risk: systematic review and meta-analysis of observational studies. .J Endocrinol Invest. 2018;41(1):33-47.

35. Erdmann J, Salmhofer H, Knauß A, Mayr M, Wagenpfeil S, Sypchenko O, et al. Relationship of fetuin-A levels to weight-dependent insulin resistance and type 2 diabetes mellitus. Regul Pept. 2012;178(1-3):6-10.

36. Ismail NA, Ragab S, Abd El Dayem SM, ElBaky AA, Salah N, Hamed M, et al. Fetuin-A levels in obesity: differences in relation to metabolic syndrome and correlation with clinical and laboratory variables. Arch Med Sci. 2012;8(5):826-33.

37. Xu Y, Xu M, Bi Y, Song A, Huang Y, Liu Y, et al. Serum fetuin-A is corretaled with metabolic syndrome in middle-aged and elderly Chinese. Atherosclerosis. 2011;216(1):180-6.

38. Ix JH, Chertow GM, Shlipak MG, Brandenburg VM, Ketteler M, Whooley MA. Association of fetuin-A with mitral annular calcification and aortic stenosis among persons with coronary heart disease: data from the Heart and Soul Study. Circulation. 2007;115(19):2533-9.

39. Hennige AM, Staiger H, Wicke C, Machicao F, Fritsche A, Häring HU, et al. Fetuin-A induces cytokine expression and suppresses adiponectin production. PLoS One. 2008;3(3):e1765.

40. Kaushik SV, Plaisance EP, Kim T, Huang EY, Mahurin AJ, Grandjean PW, et al. Extended-release niacin decreases serum fetuin-A concentrations in individuals with metabolic syndrome. Diabetes Metab Res Rev. 2009;25(5):427-34.

41. Goustin AS, Abou-Samra AB. The "thrifty" gene encoding Ahsg/Fetuin-A meets the insulin receptor: insights into the mechanism of insulin resistance. Cell Signalling. 2011;23(6):980-90.

42. Brix JM, Stingl H, Hollerl F, Schernthaner GH, Kopp HP, Schernthaner G. Elevated fetuin-A concentrations in morbid obesity decrease after dramatic weight loss. J Clin Endocrinol Metab. 2010; 95(11):4877-81.

43. Alvarez-Llamas G, Szalowska E, de Vries MP, Weening D, Landman K, Hoek A, et al. Characterization of the human visceral adipose tissue secretome. Mol Cell Proteomics. 2007; 6(4):589-600.

44. Roca-Rivada A, Al-Massadi O, Castelao C, Senín LL, Alonso J, Seoane LM, et al. Muscle tissue as an endocrine organ: comparative secretome profiling of slow-oxidative and fast-glycolytic rat muscle explants and its variation with exercise. JProteomics. 2012;75(17):5414-25.

45. Perez-Sotelo D, Roca-Rivada A, Larrosa-Garcia M, Castelao C, Baamonde I, Baltar J, et al. Visceral and subcutaneous adipose tissue express and secrete functional alpha2hsglycoprotein (fetuin a) especially in obesity. Endocrine. 2017;55(2):43546.

46. Pal D, Dasgupta S, Kundu R, Maitra S, Dias G, Mukhopadhyay S, et al. Fetuin-A acts as an endogenous ligand of TLR4 to promote lipid-induced insulin resistance. Nat Med. 2012;18(8):1279-85.

47. Weikert C, Stefan N, Schultze MB, Pischon T, Berger K, Joost HG, et al. Plasma fetuin-A levels and the risk of myocardial infarction and ischemic stroke. Circulation. 2008;118(24):2555-62.

48. Laughlin G A, Cummins KM, Wassel CL, Daniels LB, Ix JH. The association of fetuin-A with cardiovascular disease mortality in older community-dwelling adults: the Rancho Bernardo study. J Am Coll Cardiol. 2012;59(19):1688-96.

49. Mori K, Emoto M, Araki T, Yokoyama H, Teramura M, Lee E, et al. Association of serum fetuin-A with carotid arterial stiffness. Clin Endocrinol (Oxf). 2007;66(2):246-50.

50. Mukhopadhyay S, Mondal SA, Kumar M, Dutta D. Proinflammatory and antiinflammatory 
attributes of fetuin-a: a novel hepatokine modulating cardiovascular and glycemic outcomes in metabolic syndrome. Endocr Pract. 2014;20(12):1345-51.

51. Bilgir O, Kebapcilar L, Bilgir F, Bozkaya G, Yildiz Y, Pinar P, et al. Decreased serum fetuin-A levels are associated with coronary artery diseases. Intern Med. 2010;49(13):1281-5.

52. Ix JH, Katz R, de Boer IH, Kestenbaum BR, Peralta CA, Jenny NS, et al. Fetuin-A is inversely associated with coronary artery calcification in community-living persons: the Multi-Ethnic Study of Atherosclerosis. Clin Chem. 2012;58(5):88795.

53. Sun ZL, Xie QY, Guo GL, Ma K, Huang YY. Serum fetuin-A levels in patients with cardiovascular disease: a meta-analysis. BioMed Research International. 2014;2014: 691540.

54. Laugsand LE, Ix JH, Bartz TM, Djousse L, Kizer JR, Tracy RP, et al. Fetuin-A and risk of coronary heart disease: a Mendelian randomization analysis and a pooled analysis of AHSG genetic variants in 7 prospective studies. Atherosclerosis. 2015;243(1):44-52.

55. Sun Q, Jimenez MC, Townsend MK, Rimm EB, Manson JE, Albert CM, et al. Plasma levels of fetuin-A and risk of coronary heart disease in US women: the Nurses' Health Study. J Am Heart Assoc. 2014;24(3):e000939.

56. Roos M, Oikonomou D, von Eynatten M, Luppa PB, Heemann U, Lutz J, et al. Associations of fetuin-A levels with vascular disease in type 2 diabetes patients with early diabetic nephropathy. Cardiovasc Diabetol. 2010;9:48.

57. Sezer S, Uçar F, Ulusoy EK, Erdogan S, Bilen $S$, Züngün $C$, et al. Serum amyloid A, fetuin-A, and pentraxin-3 levels in patients with ischemic stroke: novel prognostic biomarkers?. Turk J Med Sci. 2014;44(1):16-23.

58. Weikert C, Berger K, Heidemann C, Bergmann MM, Hoffmann K, Klipstein-Grobusch K, et al. Joint effects of risk factors for stroke and transient ischemic attack in a German population: the EPIC Potsdam Study. J Neurol. 2007;254(3):315-21.

59. Wang YJ, Gong ZQ, Bi XM, Li YL. Correlation of plasma soluble cluster of differentiation 40 ligand, alpha fetoprotein $\mathrm{A}$, and pregnancyassociated plasma protein A with carotid plaque in patients with ischemic stroke. Genet Mol Res. 2015;14(3):8091-9.

60. Jiménez MC, Sun Q, Schürks M, Hu FB, Manson JE, Rexrode KM. Circulating fetuin-A and risk of ischemic stroke in women. Clin Chem. 2014;60(1):165-73.

61. Wang H, Li W, Zhu S, Li J, D‘Amore J, Ward
MF, et al. Peripheral administration of fetuin-A attenuates early cerebral ischemic injury in rats. J Cereb Blood Flow Metab. 2010;30(3):493-504.

62. Asuncion M, Calvo RM, San Millan JL, Sancho J, Avila S, Escobar-Morreale HE. A prospective study of the prevalence of the polycystic ovary syndrome in unselected Caucasian women from Spain. J Clin Endocrinol Metab. 2000;85(7):24348.

63. Sirmans SM, Pate KA. Epidemiology, diagnosis, and management of polycystic ovary syndrome. Clin Epidemiol. 2013;6:1-13.

64. Hart R, Hickey M, Franks S. Definitions, prevalence and symptoms of polycystic ovaries and polycystic ovary syndrome. Best Pract Res Clin Obstet Gynaecol. 2004;18(5):671-83.

65. Dunaif A Insulin resistance and the polycystic ovarysyndrome: mechanism and implications for pathogenesis. Endocr Rev. 1997;18(6):774-800.

66. Enli Y, Fenkci SM, Fenkci V, Oztekin O. Serum fetuin-A levels, insulin resistance and oxidative stress in women with polycystic ovary syndrome. Gynecol Endocrinol. 2013;29(12):1036-9.

67. Hasan AL-Aboudy NF, Hussain AL-Ani NK, Reda AlKawaz UM. The effect of different ovarian stimulation protocols on multifunctional fetuin_A concentration in the serum and follicular fluid of women with PCOS undergoing ICSI/IVF. Int. J. of Adv. Res. 2017;5(9):1012-9.

68. Okohue JE, Onuh SO, Ikimalo JI. Comparison of IVF/ICSI outcome in patients with polycystic ovarian syndrome or tubal factor infertility. Niger J Clin Pract. 2013;16(2):207-10.

69. Farhan S, Handisurya A, Todoric J, Tura A, Pacini $\mathrm{G}$, Wagner $\mathrm{O}$, et al. Fetuin-A characteristics during and after pregnancy: result from a case control pilot study. Int J Endocrinol. 2012;896736.

70. Kalabay L, Cseh K, Pajor A, Baranyi E, Csákány GM, Melczer Z, et al. Correlation of maternal serum fetuin/alpha2-HS-glycoprotein concentration with maternal insulin resistance and anthropometric parameters of neonates in normal pregnancy and gestational diabetes. Eur J Endocrinol. 2002;147(2):243-8.

71. Abali R, Celik C, Tasdemir N, Guzel S, Alpsoy S, Yuksel A, et al. The serum protein $\alpha 2$-HeremansSchmid glycoprotein/fetuin-A concentration and caroid intima-media thickness in women with polycystic ovary syndrome. Eur J Obstet Gynecol Reprod Biol. 2013;169(1):45-9.

72. Gulhan I, Bozkaya G, Ozetkin D, Uyar I, Kebapsilar AG, Pamuk B. Serum fetuin-A levels in women with polycystic ovary syndrome. Arch Gynecol Obstet. 2012;286(6):1473-6. 